\title{
Powering Analysis of Oscillating Foil Moving in Propagating Wave Flow Field
}

\author{
Yoon-Rak Choi@* \\ *School of Naval Architecture and Ocean Engineering, University of Ulsan, Ulsan, Korea \\ 전파하는 파동유장 중 전진하며 동요하는 2차원 날개의 동력해석 \\ 최윤락(1) \\ "울산대학교 조선해양공학부
}

KEY WORDS: Time-mean power 시간평균 동력, Wave flow field 파동 유동장, Oscillating foil 동요하는 날개, Perturbation theory 섭동 법, Quadratic transfer function 2차 전달함수

\begin{abstract}
In this study, a two-dimensional oscillating foil with forward speed in a propagating wave flow field was considered. The time-mean power to maintain the heaving and pitching motions of the foil was analyzed using the perturbation theory in an ideal fluid. The power, which was a non-linear quantity of the second-order, was expressed in terms of the quadratic transfer functions related to the mutual product of the heaving and pitching motions and incoming vertical flow. The effects of the pivot point and phase difference among the disturbances were studied. The negative power, which indicates energy extraction from the fluid, is shown as an example calculation.
\end{abstract}

\section{1. 서 론}

동요하는 날개에 의한 유체력을 활용하는 분야로는 선박의 핀 또는 타를 이용한 횡동요 저감(Perez, 2005), 조류의 비행 및 어류의 유영(Lighthill, 1975; Azuma, 2006; Wu, 1971) 등이 있다. 또한 조류(Current) 중 동요하는 날개를 활용하여 에너지를 취득 하는 시스템에도 사용되고 있다(Xiao and Zhu, 2014).

비정상 날개 이론은 Theodorsen(1935)이 조화 운동하는 날개 에 작용하는 양력을 Theodorsen함수를 도입하여 해석함으로써 본격적으로 연구되기 시작하였다. Sears(1941)는 파동유장 중 동 요하지 않는 날개에 작용하는 양력을 Sears함수를 사용하여 해 석하였다. Garrick(1936)과 Greenberg(1947)는 각각 동요하는 날 개와 파동유장 중 고정된 날개에서 발생되는 추력을 해석하였 다. Choi(2012)는 전파하는 파동유장 중 동요하는 날개에 대한 추력을 2 차 전달함수를 사용하여 표현하였다. 이를 토대로 Choi(2013)는 파랑 중 동요하는 날개가 부착된 선박의 추력발생 을 해석하여 실험결과와 비교하였다.

본 연구에서는 Choi(2012)의 2차원 비정상 날개 해석법을 사
용하여 파동유장 중 동요하는 날개에 소요되는 동력(Power)을 2 차 전달함수로 도출하였다. 날개의 상하동요, 종동요, 그리고 파 동유의 상호 위상차와 회전점(Pivot point)위치에 따른 동력변화 를 살펴보았다. 또한, 해석 예로서 주어진 동요크기 및 파동유 장에 대하여 동력계수를 계산하여 유체로부터 에너지를 공급받 아 날개가 동요할 수 있음을 확인하였다.

\section{2. 문제의 정식화 및 선형 문제 해석}

전파하는 수직 조화 파동유장과 2차원 날개운동을 Choi(2012) 에 따라 정의한다. Fig. 1은 음의 $X$ 방향으로 전파하는 수직 조 화 파동유장으로 그림에서 $\lambda, K, \nu, V_{p}$, 그리고 $v_{g}(X, t)$ 는 각각 파동유장의 파장, 파수, 진동수, 전파속도, 그리고 수직방향 유 체속도이며, $W$ 는 수직속도의 복소 진폭이다.

이러한 유장에 양의 $X$ 방향으로 일정속도 $U$ 로 진행하며 상하 동요 및 종동요하는 2차원 날개를 Fig. 2에 도시하였다. 그림에 서 $l$ 은 날개의 길이(Chord length)이고, $\lambda_{w}$ 는 파동유장 및 날개 동요에 의한 후류와도(Vortex wake)의 파장이다. 날개 평균위치

Received 8 February 2019, revised 9 May 2019, accepted 13 June 2019

Corresponding author Yoon-Rak Choi: +82-52-259-2158, yrchoi@ulsan.ac.kr ORCID: https://orcid.org/0000-0002-3865-6721

(c) 2019, The Korean Society of Ocean Engineers

This is an open access article distributed under the terms of the creative commons attribution non-commercial license (http://creativecommons.org/licenses/by-nc/3.0) which permits unrestricted non-commercial use, distribution, and reproduction in any medium, provided the original work is properly cited. 


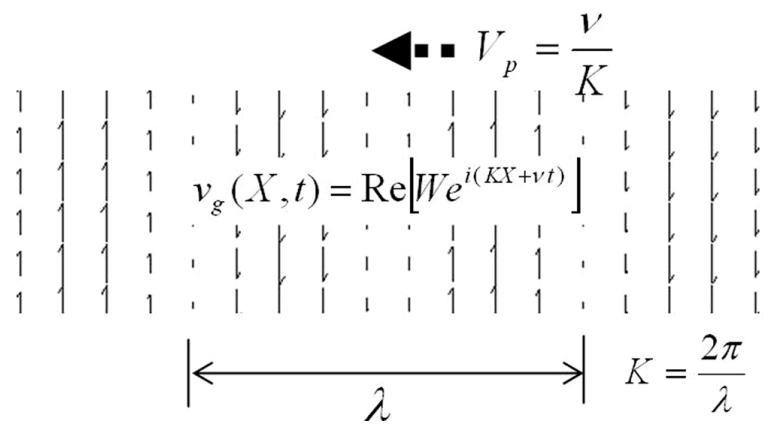

Fig. 1 Propagating oscillatory flow field

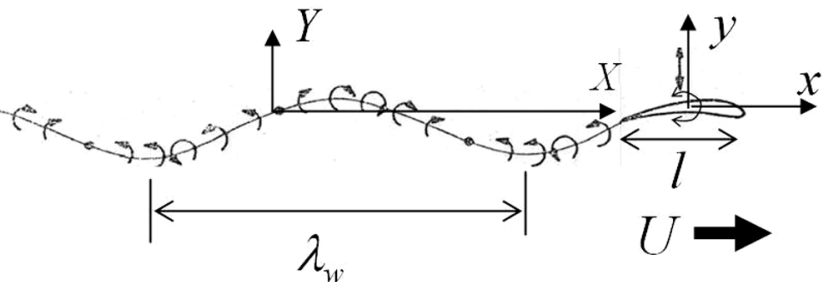

Fig. 2 Oscillating foil with forward speed

에 고정된 물체고정좌표계에 대해서는 Fig. 1의 수직 파동유장 이 $U$ 의 속도로 음의 $x$ 방향으로 유입되는 것으로 간주되며 유 입 파동 유장은 식 (1)로 표현된다.

$$
v_{g}(x, t)=\operatorname{Re}\left[W e^{i\left(K x+\omega_{e} t\right)}\right]
$$

여기서, $\omega_{e}$ 는 조우진동수(Frequency of encounter) 이며 식 (2)와 같다.

$$
\omega_{e}=K U+\nu
$$

날개의 운동은 능동형(Active type) 또는 피동형(Passive type) 작동시스템에 의해 조화운동한다고 가정하고 운동 진동수는 조 우진동수와 동일하다고 가정한다. 이에 따라 파동유장에 의한 유체력과 운동에 의한 유체력은 모두 조우진동수로 변동하며 각각에 의한 후류와도의 파장도 동일하다.

$$
\lambda_{w}=\frac{2 \pi U}{\omega_{e}}
$$

유체는 이상유체라 가정한다. 그리고 날개의 두께와 수직운동 의 크기가 날개 길이에 비해 매우 작다는 가정을 도입한다. 또 한 수직 파동류의 속도크기가 전진속도 $U$ 에 비해 매우 작다고 가정(|W<<U)하면 섭동법(Perturbation method)에 따라 선형 양 력문제(Linear lifting problem)를 구성할 수 있다. 동요하는 날개 면 위에서의 수직방향 유속은 $y=0$ 에서 평균 캠버선 $\eta(x, t)$ 의 운동과 기울기에 의해 식 (4)로 표현된다(Newman, 1977).

$$
v(x, 0, t)=\frac{\partial \eta}{\partial t}-U \frac{\partial \eta}{\partial x} \equiv v_{0}(x, t) \quad \text { for } \quad-\frac{l}{2}<x<\frac{l}{2}
$$

식 (4)의 물체경계조건은 선형 중첩의 원리에 의해 파동유장 이 없는 상태에서 전진하며 수직 조화운동하는 날개에 대한 경 계조건과 전진하며 동요하지 않는 평판에 수직 파동류가 입사 될 때의 경계조건으로 분리될 수 있다.

$$
\begin{aligned}
& v_{0}(x, t)=v_{0 m}(x, t)+v_{0 s}(x, t)+v_{g}(x, t) \\
& v_{0 m}(x, t)=\frac{\partial \eta}{\partial t}-U \frac{\partial \eta}{\partial x}=\operatorname{Re}\left[v_{m}(x) e^{i \omega_{e} t}\right] \\
& v_{0 s}(x, t)=-v_{g}(x, t)=-\operatorname{Re}\left[W^{i K x} e^{i \omega_{e} t}\right]
\end{aligned}
$$

식 (6)-(7)의 물체 경계조건과 날개 뒷전(Trailing edge)에서의 Kutta조건 및 후류와도면 상하에서의 압력 연속조건을 만족하는 해로 부터 날개에 작용하는 양력과 모멘트를 계산할 수 있다 (Garrick, 1936; Sears, 1941; Kaplan, 1955).

$$
\begin{aligned}
& L_{m}=-2 \rho U^{2}\left(\frac{l}{2}\right) \operatorname{Re}\left[e^{i \omega_{\epsilon} t}\left\{C(k) I_{1}+i k I_{3}\right\}\right] \\
& M_{m}=-\rho U^{2}\left(\frac{l}{2}\right)^{2} \operatorname{Re}\left\{e ^ { i \omega _ { \epsilon } t } \left[\left\{\left(\begin{array}{l}
\left.\left.\left.1-\frac{4 a}{l}\right) C(k)-1\right\} I_{1}+2 I_{3}\right] \\
+i k\left(I_{4}-\frac{4 a}{l} I_{3}\right)
\end{array}\right]\right\}\right.\right. \\
& L_{g}=2 \pi \rho U^{2}\left(\frac{l}{2}\right) \operatorname{Re}\left\{e^{i \omega_{\epsilon} t} \frac{W}{U} S(k, \mu)\right\} \\
& \left.M_{g}=\pi \rho U^{2}\left(\frac{l}{2}\right)^{2} \operatorname{Re}\left\{e^{i \omega_{e} t} \frac{W}{U}\left[\left(\begin{array}{l}
\left.1-\frac{4 a}{l}\right) S(k, \mu) \\
+\left(1-\frac{k}{\mu}\right)
\end{array}\right)\left(i+\frac{2}{\mu}\right) J_{1}(\mu)-J_{0}(\mu)\right\}\right]\right\}
\end{aligned}
$$

여기서, 밑첨자 $m$ 과 $g$ 는 각각 날개의 운동과 파동유장에 의한 양력과 모멘트를 나타내고 $a$ 는 모멘트 중심이며 전체 양력과 모멘트는 각각 $L=L_{m}+L_{g}$ 와 $M=M_{m}+M_{g}$ 이다. 즉, $L_{m}$ 과 $M_{m}$ 은 파동유장이 없는 상태에서 전진하며 동요하는 날개의 경계조건 인 식 (6)을 만족하는 해로부터 구한 양력과 모멘트이고, $L_{g}$ 과 $M_{g}$ 는 전파하는 파동 수직유장 중 전진하며 동요하지 않는 날개 의 경계조건인 식 (7)을 만족하는 해로부터 구한 양력과 모멘트 이다. 그리고 $C(k)$ 와 $S(k, \mu)$ 는 각각 Bessel 함수들로 표현되는 Theordorsen 함수와 확장된 Sears 함수로 무차원 파라미터인 $k$ (Reduced frequency)와 $\mu$ 의 함수이다(Choi, 2012).

$$
\begin{aligned}
& C(k)=\frac{H_{1}^{(2)}(k)}{H_{1}^{(2)}(k)+i H_{0}^{(2)}(k)} \equiv F(k)+i G(k) \\
& S(k, \mu)=C(k)\left\{J_{0}(\mu)-i J_{1}(\mu)\right\}+i \frac{k}{\mu} J_{1}(\mu) \\
& k=\frac{\omega_{e} l}{2 U}=\frac{\pi l}{\lambda_{w}} \\
& \mu=\frac{K l}{2}=\frac{\pi l}{\lambda}
\end{aligned}
$$


또한, 식 (8)-(9)에서 보이는 $I_{1}, I_{3}$, 그리고 $I_{4}$ 는 날개 운동에 의해 야기된 수직방향 유속 $v_{m}(x)$ 의 적분 값들로 다음과 같다.

$$
\begin{aligned}
& I_{1}=\frac{2}{l} \int_{-l / 2}^{l / 2} \sqrt{\frac{\frac{l}{2}-\xi}{\frac{l}{2}+\xi}} \frac{v_{m}(\xi)}{U} d \xi \\
& I_{3}=\left(\frac{2}{l}\right)^{2} \int_{-l / 2}^{l / 2} \sqrt{\left(\frac{l}{2}\right)^{2}-\xi^{2}} \frac{v_{m}(\xi)}{U} d \xi \\
& I_{4}=\left(\frac{2}{l}\right)^{3} \int_{-l / 2}^{l / 2} \xi \sqrt{\left(\frac{l}{2}\right)^{2}-\xi^{2}} \frac{v_{m}(\xi)}{U} d \xi
\end{aligned}
$$

이상의 선형문제 해석결과는 Choi(2012)에도 기술되어 있다.

\section{3. 날개 동력 해석}

날개가 유체력에 대응되는 반작용력을 유체에 가하며 운동을 유지하기 위해서는 동력이 요구된다. 강체 날개의 경우 조화운 동을 유지하기 위해 소요되는 시간평균동력(Time mean power) 은 식 (19)와 같으며, 이는 2차항의 비선형 물리량이다.

$$
\bar{P}=-\overline{\dot{q} L}-\overline{\dot{\alpha} M}=-\overline{\dot{q} L_{m}}-\overline{\dot{\alpha} M_{m}}-\overline{\dot{q} L_{g}}-\overline{\dot{\alpha} M_{g}}
$$

여기서, $\dot{q}$ 는 모멘트 중심으로 설정한 회전점 $(a)$ 에서의 날개 상 하동요 속도이며 $\dot{\alpha}$ 는 날개 종동요 각속도이다(Fig. 3). 식 (20) 의 조화운동 가정에 따라 식 (8)-(11)의 힘과 모멘트들에 대응하 는 동력을 계산하면 다음과 같다.

$$
\begin{aligned}
& q=\operatorname{Re}\left[q_{0} e^{i \omega_{\epsilon} t}\right], \quad \alpha=\operatorname{Re}\left[\alpha_{0} e^{i \omega_{\epsilon} t}\right] \\
& \bar{P}=\overline{P_{L_{m}}}+\overline{P_{M_{m}}}+\overline{P_{L_{g}}}+\overline{P_{M_{g}}} \\
& \overline{P_{L_{m}}}=\rho U^{3}\left(\frac{l}{2}\right) k\left[\left\{\left\{\frac{q_{0}}{l} C^{*}(k) I_{1}^{*}-(*)\right\}+k\left(\frac{q_{0}}{l} I_{3}^{*}+\left(^{*}\right)\right)\right]\right. \\
& \overline{P_{M_{m}}}=\frac{1}{4} \rho U^{3}\left(\frac{l}{2}\right) k\left[\begin{array}{l}
i\left(\alpha_{0}\left(\left(1-\frac{4 a}{l}\right) C^{*}(k)-1\right\} I_{1}^{*}-(*)\right) \\
+2 i\left(\alpha_{0} I_{3}^{*}-(*)\right)+k\left\{\alpha_{0}\left(I_{4}^{*}-\frac{4 a}{l} I_{3}^{*}\right)+(*)\right\}
\end{array}\right] \\
& \overline{P_{L_{g}}}=-\pi \rho U^{3}\left(\frac{l}{2}\right) k\left[i\left\{\frac{q_{0}}{l} \frac{W^{*}}{U} S^{*}(k, \mu)-(*)\right\}\right] \\
& \overline{P_{M_{g}}}=-\frac{1}{4} \pi \rho U^{3}\left(\frac{l}{2}\right) k \\
& \times\left[\begin{array}{l}
i\left(1-\frac{4 a}{l}\right)\left\{\alpha_{0} \frac{W^{*}}{U} S^{*}(k, \mu)-(*)\right\} \\
+\left(1-\frac{k}{\mu}\right)\left\{\begin{array}{l}
\left(\alpha_{0} \frac{W^{*}}{U}+(*)\right) J_{1}(\mu) \\
+i\left(\frac{2}{\mu} J_{1}(\mu)-J_{0}(\mu)\right)\left(\alpha_{0} \frac{W^{*}}{U}-(*)\right)
\end{array}\right\}
\end{array}\right\}
\end{aligned}
$$

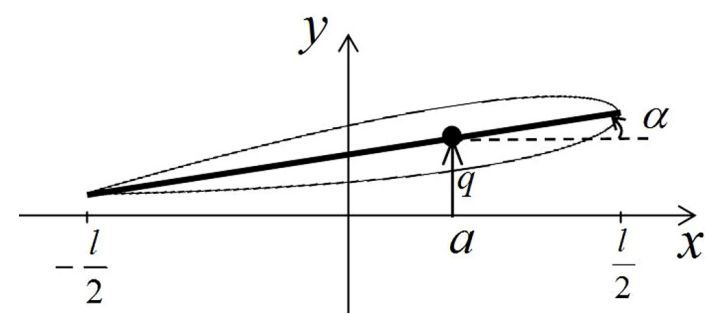

Fig. 3 Heaving and pitching motions of a foil at a pivot point

여기서, 윗 첨자 *는 공액복소수를 의미하며, 음 또는 양의 부 호 뒤의 $\left(^{*}\right)$ 는 부호 앞 항의 공액복소수를 의미한다. 그리고, $q_{0}$ 와 $\alpha_{0}$ 는 각각 상하동요와 종동요의 복소 진폭으로 운동의 진폭 과 위상각을 복소수 형태로 표현한 것이다.

\section{4. 평판 날개에 대한 적용}

섭동법에 의한 해석을 수행하면 강체 날개가 곡선의 캠버형 상을 가지더라도 동요에 의한 영향은 상하대칭 날개에 해당하 는 평판 날개의 동요와 동일하며, 곡선형상의 영향은 정적인 양 력으로 간주된다. 따라서 본 연구에서는 평판 날개의 동요에 대 한 동력해석을 수행한다.

평판 날개의 수직운동은 식 (26)으로 표현된다.

$$
\eta(x, t)=q(t)+\alpha(t)(x-a)
$$

식 (20)의 조화운동을 가정하면 동요하는 날개위에서의 수직 유동 복속 진폭 $v_{m}(x)$ 은 식 (6)에 의해 다음과 같이 표현된다.

$$
v_{m}(x)=i \omega_{e}\left[q_{0}+\alpha_{0}(x-a)\right]-U \alpha_{0}
$$

따라서, 식 (16)-(18)의 적분을 수행하면 다음의 결과를 얻는다.

$$
\begin{aligned}
& I_{1}=2 \pi\left[i k \frac{q_{0}}{l}-\left\{1+i \frac{k}{2}\left(1+\frac{4 a}{l}\right)\right\} \frac{\alpha_{0}}{2}\right] \\
& I_{3}=\pi\left\{i k \frac{q_{0}}{l}-\left(1+i k \frac{2 a}{l}\right) \frac{\alpha_{0}}{2}\right\} \\
& I_{4}=\frac{\pi}{8} i k \alpha_{0}
\end{aligned}
$$

식 (28)-(30)을 식 (8)-(9)에 대입하면 조화 운동하는 평판에 작 용하는 양력과 모멘트를 구할 수 있으며 그 결과는 Choi(2012) 에 나와 있다. 또한, 식 (28)-(30)을 식 (22)-(23)에 대입하면 $\overline{P_{L_{m}}}$ 과 $\overline{P_{M_{m}}}$ 을 운동 복소진폭 $q_{0}$ 와 $\alpha_{0}$ 의 곱들로 표현할 수 있다. 그 리고 파동류 관련 동력인 식 (24)-(25)는 $q_{0}$ 와 $W$, 그리고 $\alpha_{0}$ 와 $W$ 으로 곱으로 표현된다. 이러한 선형 물리량들의 곱에 비례하 는 동력은 2차 전달함수(Quadratic transfer function)들로 표현되 며 다음과 같이 정리된다. 


$$
\begin{aligned}
& C_{P} \equiv \frac{\bar{P}}{\frac{1}{2} \rho U^{3} l}=\left|\frac{q_{0}}{l}\right|^{2} H_{P q q}+\left|\alpha_{0}\right|^{2} H_{P \alpha \alpha}+\left|\frac{q_{0}}{l}\right|\left|\alpha_{0}\right| H_{P q \alpha} \\
& +\left|\frac{q_{0}}{l}\right|\left|\frac{W}{U}\right| H_{P q W}+\left|\alpha_{0}\right|\left|\frac{W}{U}\right| H_{P \alpha W}
\end{aligned}
$$

여기서, $C_{P}$ 는 시간평균 동력계수(Time-mean power coefficient)이 고, $F$ 와 $G$ 는 각각 $F(k)$ 와 $G(k)$ 를 의미하며, $\theta$ 들은 각 물리량의 복소 진폭 위상각이다.

$$
q_{0}=\left|q_{0}\right| e^{i \theta_{q}}, \alpha_{0}=\left|\alpha_{0}\right| e^{i \theta_{\alpha}}, \quad W=|W| e^{i \theta_{W}}
$$

식 (32)-(36)의 2차 전달함수들을 살펴보면 다른 물리량들의 곱에 해당하는 전달함수들은 물리량들 간의 위상차의 함수이고 종동요와 관련된 전달함수들은 회전점 $a$ 의 함수이다. 그리고 파동유장 관련 전달함수들은 식 (15)로 정의된 $\mu$ 의 함수로 이는 파동유장 파장에 대한 날개길이의 비이다.

수중 날개에 유입되는 파동류들로는 파도, 프로펠러 후류 등 이 있다. 파도의 경우 파장은 날개길이보다 훨씬 긴 경우가 대 부분이므로 $\mu \ll 1$ 로 볼 수 있다. 이 경우, 식 (35)-(36)은 $J_{0}(\mu)$ 와 $J_{1}(\mu)$ 의 점근 거동을 사용하면 다음 식들로 근사 된다.

$$
\begin{aligned}
& H_{P q W}=2 \pi k\left[-\left(G+\frac{k}{2}\right) \cos \left(\theta_{q}-\theta_{W}\right)+F \sin \left(\theta_{q}-\theta_{W}\right)+O(\mu)\right] \\
& H_{P \alpha W}=\frac{\pi}{2} k\left[\begin{array}{l}
\left\{-\left(1-\frac{4 a}{l}\right) G+k \frac{2 a}{l}\right\} \cos \left(\theta_{\alpha}-\theta_{W}\right) \\
+\left(1-\frac{4 a}{l}\right) F \sin \left(\theta_{\alpha}-\theta_{W}\right)+O(\mu)
\end{array}\right]
\end{aligned}
$$

또 다른 주요 비선형 물리량인 시간평균 추력에 대한 2차 전 달함수는 Choi(2012)에 나와 있다.

\section{5. 평판 날개에 대한 동력 2차 전달함수 해석}

식 (32)로 표현되는 $H_{P q q}$ 는 $k$ 의 함수로 Fig. 4에 도시되어 있
다. 모든 $k$ 값에서 양의 값을 가지며 $k$ 가 증가할수록 $H_{P q q}$ 값은 단조 증가한다. 식 (33)으로 표현되는 $H_{P \alpha \alpha}$ 는 $k$ 와 $a / l$ 의 함수로 Fig. 5에 도시되어 있으며, 이 역시 양의 값을 가지며 $k$ 에 대해 서 단조 증가한다. 그런데 회전점이 뒷전 쪽인 $a / l=-1 / 4$ 지점에 있을 때 매우 작은 값을 가진다. 즉, $H_{P \alpha \alpha}$ 만 고려하면 회전점이 뒷전 쪽에 있는 것이 동력소모를 줄일 수 있다. 한 가지 흥미로 운 점은 Choi(2012)의 추력 2차 전달함수 $H_{T \alpha \alpha}$ 는 음의 값을 가 지는 경우도 있으나, 본 연구에서 해석한 동력 2차 전달 함수인 $H_{P \alpha \alpha}$ 는 항상 양의 값을 가진다는 점이다.

Fig. 6에 $H_{P q \alpha}$ 를 도시하였다. 그림에 표시된 위상차에 $180^{\circ}$ 를 더한 위상차에 대한 값은 부호를 바꾸면 된다. 회전점이 앞전 쪽이나 중앙에 위치한 경우(Fig. 6(a)-6(b)) 상하동요의 위상이 종동요의 위상에 비해 $180^{\circ}$ 정도 앞설 때 동력이 많이 소모되며 위상이 동일 할 때는 전달함수 값이 음이 되어 유체로부터 동

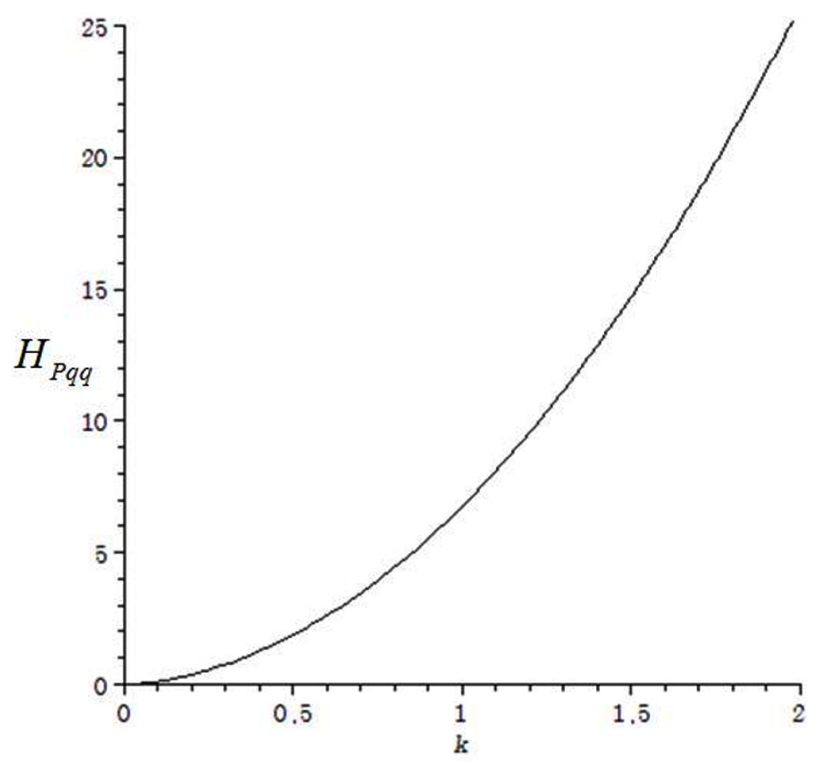

Fig. 4 Quadratic transfer function $H_{P q q}$

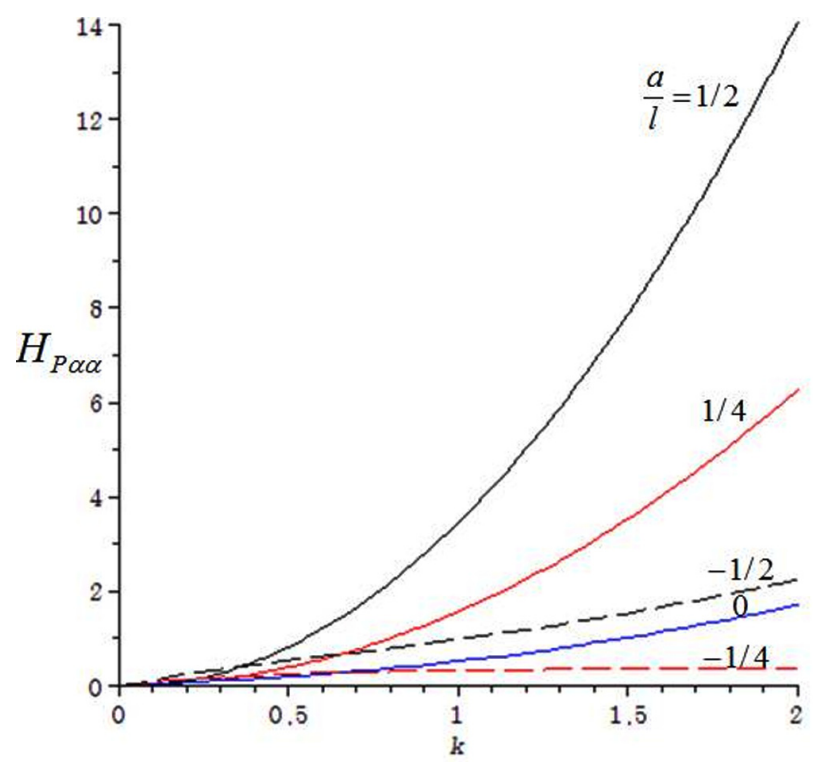

Fig. 5 Quadratic transfer function $H_{P \alpha \alpha}$ 


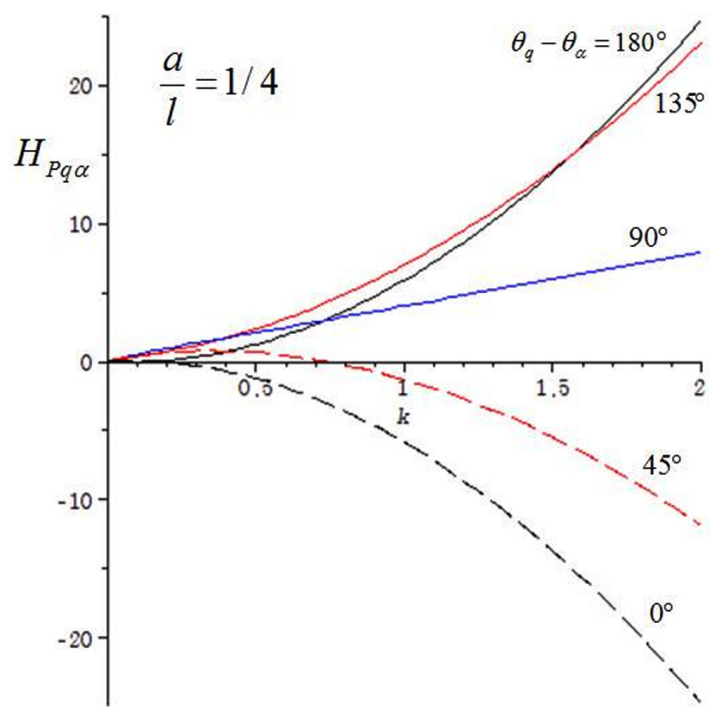

(a) $a / l=1 / 4$

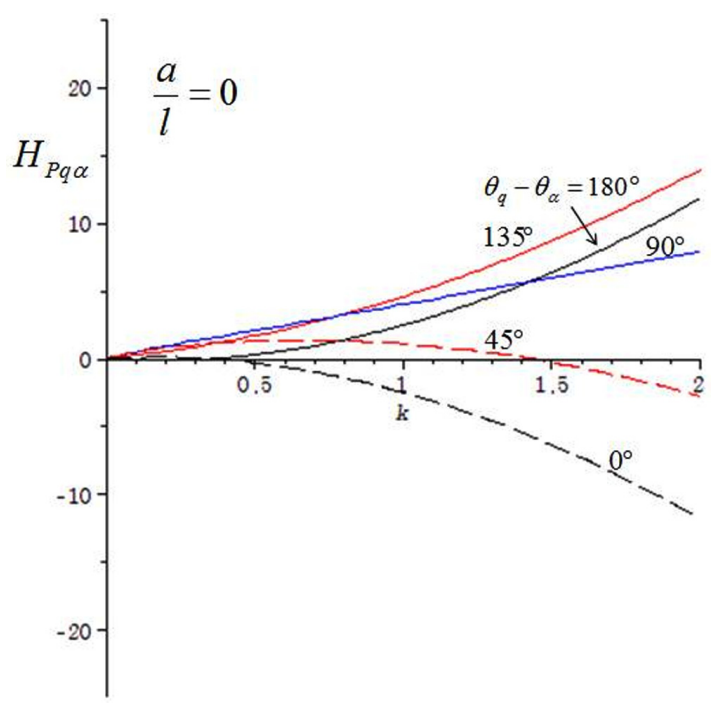

(b) $a / l=0$

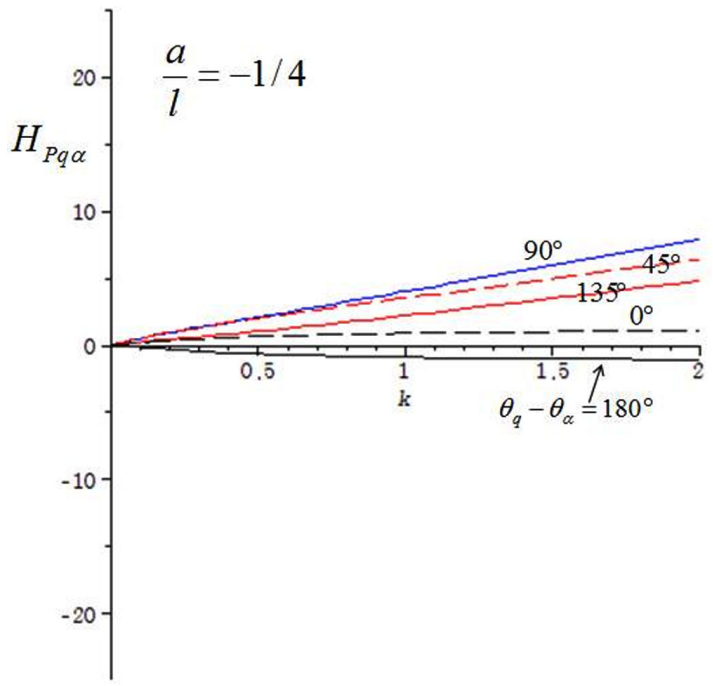

(c) $a / l=-1 / 4$

Fig. 6 Quadratic transfer function $H_{P q \alpha}$

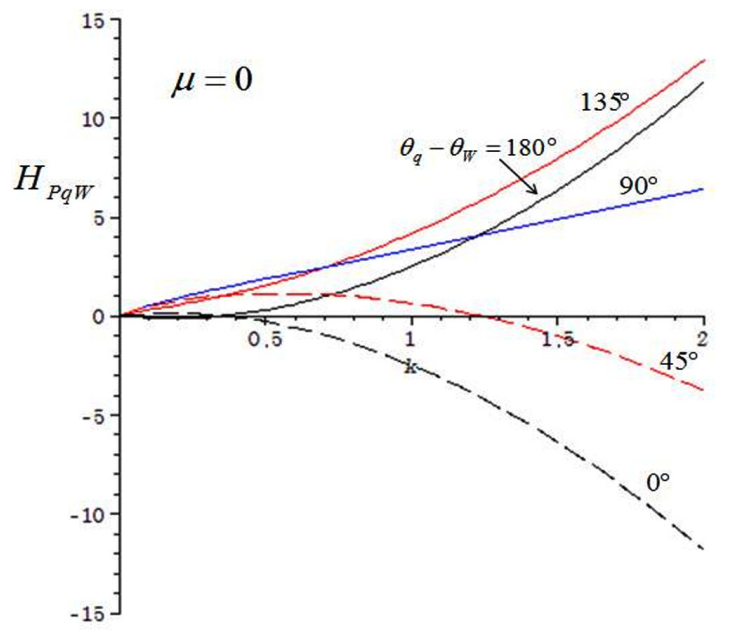

Fig. 7 Quadratic transfer function $H_{P q W}$

력을 얻을 수 있다. 그러나 회전점이 $a / l=-1 / 4$ 에 위치할 때는 위상차가 $90^{\circ}$ 부근에서 큰 양의 동력이 요구되고 $0^{\circ}$ 나 $180^{\circ}$ 부근 에서는 동력 값이 매우 작음을 알 수 있다. 이를 달리 말하면 위상차가 $270^{\circ}$ (또는 $-90^{\circ}$ )부근 일 때는 음의 동력 값을 가진다.

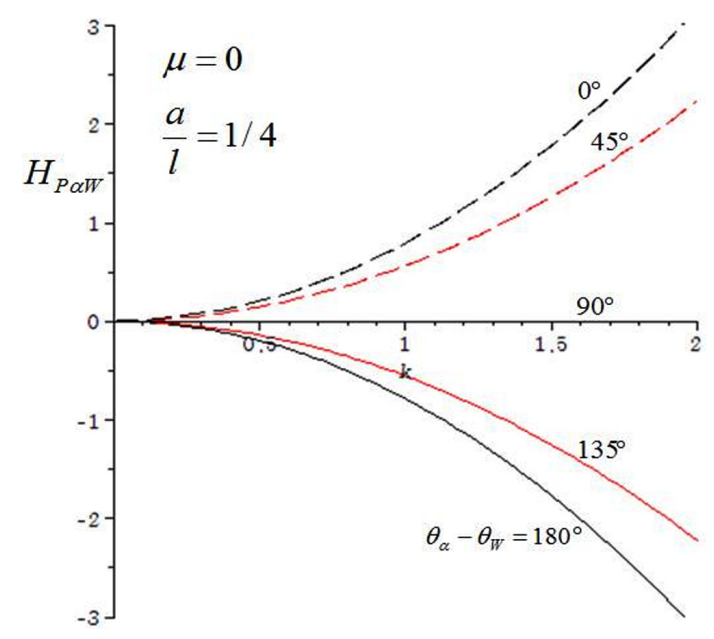

(a) $a / l=1 / 4$

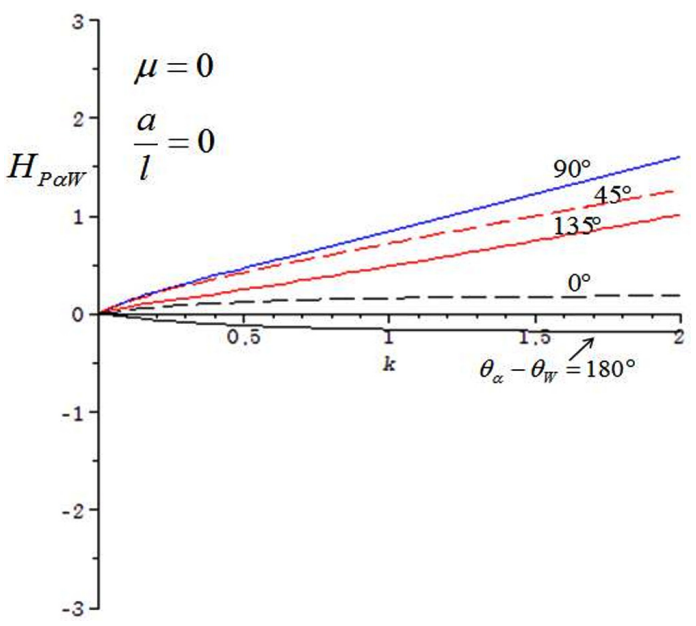

(b) $a / l=0$

Fig. 8 Quadratic transfer function $H_{P \alpha W}$ 


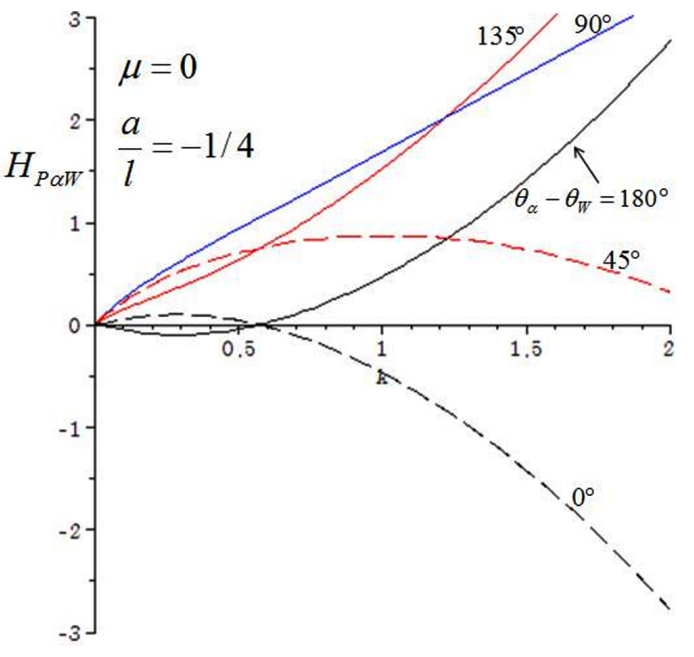

(c) $a / l=-1 / 4$

Fig. 8 Quadratic transfer function $H_{P \alpha W}$ (continuation)

상하동요와 파동유장간의 상호작용에 의한 $H_{P q}$ 를 Fig. 7 에 도시하였다. $H_{P q}$ 는 $\mu$ 의 함수이나 그림에는 파동유장 파장이 날 개길이에 비해 매우 긴 $\mu=0$ 일 때의 값을 도시하였다. 함수 값의 거동은 회전점이 중앙에 위치 해 있을 때의 $H_{P q \alpha}(\mathrm{Fig} .6(\mathrm{~b}))$ 와 유 사하다.

Fig. 8 에 $\mu=0$ 인 경우의 $H_{P \alpha}$ 를 도시하였다. 회전점의 위치 에 따라 함수 값의 거동이 상당히 다른 양상을 보인다. 특히 회 전점이 $a / l=-1 / 4$ 에 위치한 Fig. $8(\mathrm{c})$ 의 경우, 종동요와 파동유 장간의 위상차 변화에 대하여 함수 값이 상당히 복잡한 양상을 보인다.

\section{6. 평판 날개에 대한 시간평균 동력계수 해석 예}

평판 날개에 대한 시간평균 동력계수 $C_{P}$ 의 해석 예로서 Table 1 의 조건에서 해석을 수행하였다. 표에서 $\theta_{q}-\theta_{\alpha}$ 는 $\theta_{q}-\theta_{W}$ 와 $\theta_{\alpha}-\theta_{W}$ 에 의해 결정된다. $|W / U|=0.0$ 인 경우는 파동유장이 없 음을 뜻하고, 이 경우 위상차들 중 $\theta_{q}-\theta_{\alpha}$ 값만 의미가 있다. 모든 경우 수직 파동유장의 파장은 날개길이에 비해 매우 길다고 가 정하여 $\mu=0$ 을 사용하였다.

Table 1의 조건에 대한 시간평균 동력계수 해석 결과를 Fig. 9 에 도시하였다. 회전점이 뒷전 쪽에 있을수록 동력계수가 작아 짐을 볼 수 있다. Fig. $9(\mathrm{c})$ 를 보면 회전점이 $a / l=-1 / 4$ 에 위치할 때 넓은 영역의 $k$ 값에서 음의 동력계수를 보여 유체로부터 에 너지를 흡수하며 날개가 동요함을 알 수 있다. 또한 파동류의 크기가 증가 할수록 음의 동력계수 크기가 증가하여 파동류로 부터의 에너지 흡수가 날개 동요의 주요 동력원이 될 수 있다. 상하동요와 종동요의 파동유장에 대한 위상차 변화에 따른 $C_{P}$

Table 1 Conditions for example calculation

\begin{tabular}{ccccccc}
\hline \hline$a / l$ & $\left|q_{0} / l\right|$ & $\left|\alpha_{0}\right|$ & $|W / U|$ & $\theta_{q}-\theta_{W}$ & $\theta_{\alpha}-\theta_{W}$ & $\theta_{q}-\theta_{\alpha}$ \\
\hline$\{0.25$, & & & $\{0.0$, & & & \\
0, & 0.1 & 0.2 & 0.1, & $-135^{\circ}$ & $-45^{\circ}$ & $-90^{\circ}$ \\
$-0.25\}$ & & & $0.2\}$ & & & \\
\hline
\end{tabular}

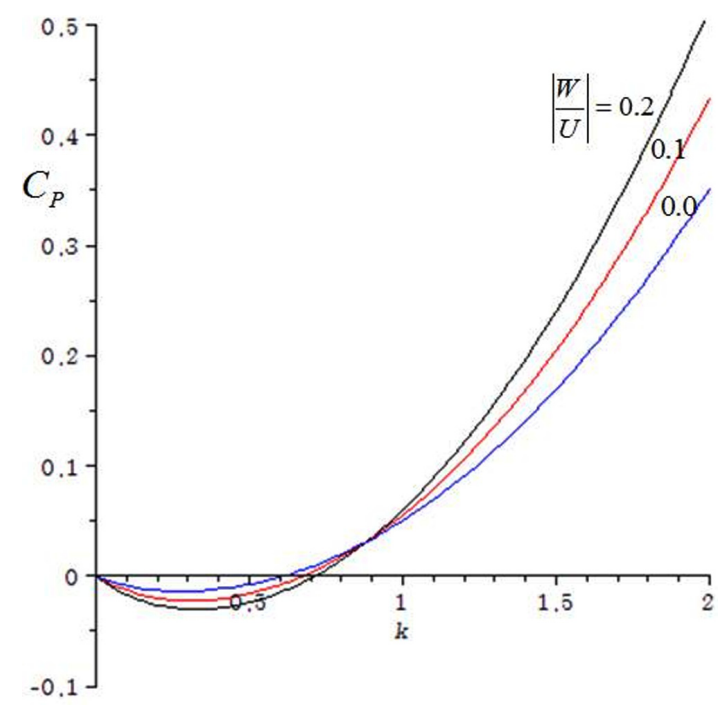

(a) $a / l=1 / 4$

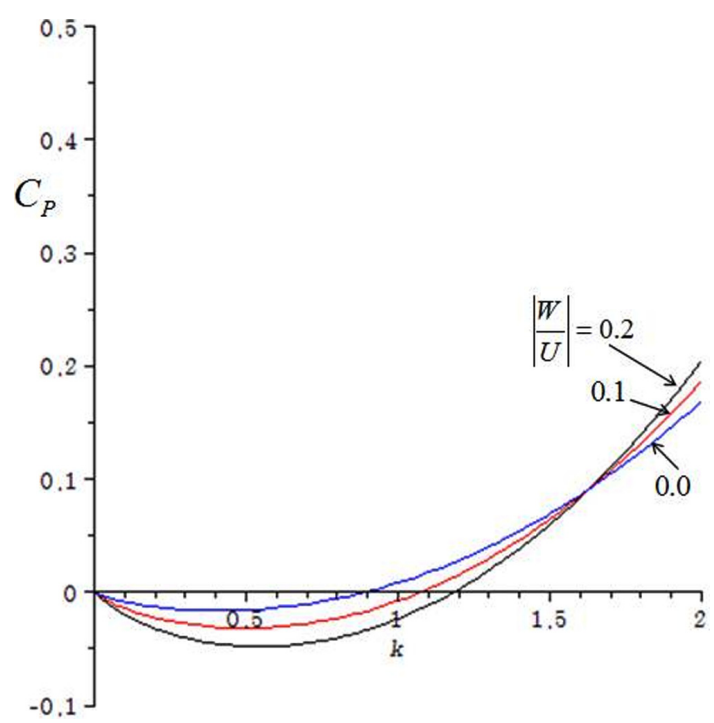

(b) $a / l=0$

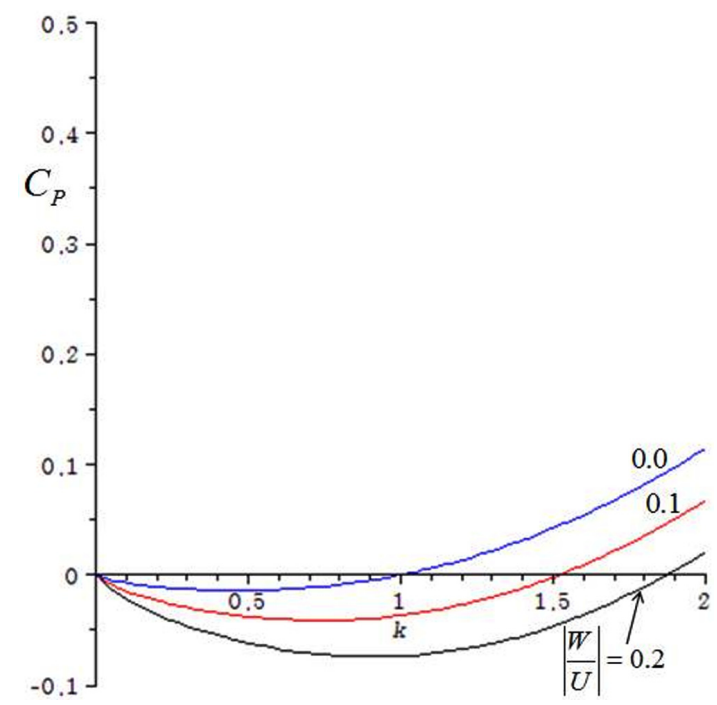

(c) $a / l=-1 / 4$

Fig. 9 Time-mean power coefficients for the conditions in Table 1 


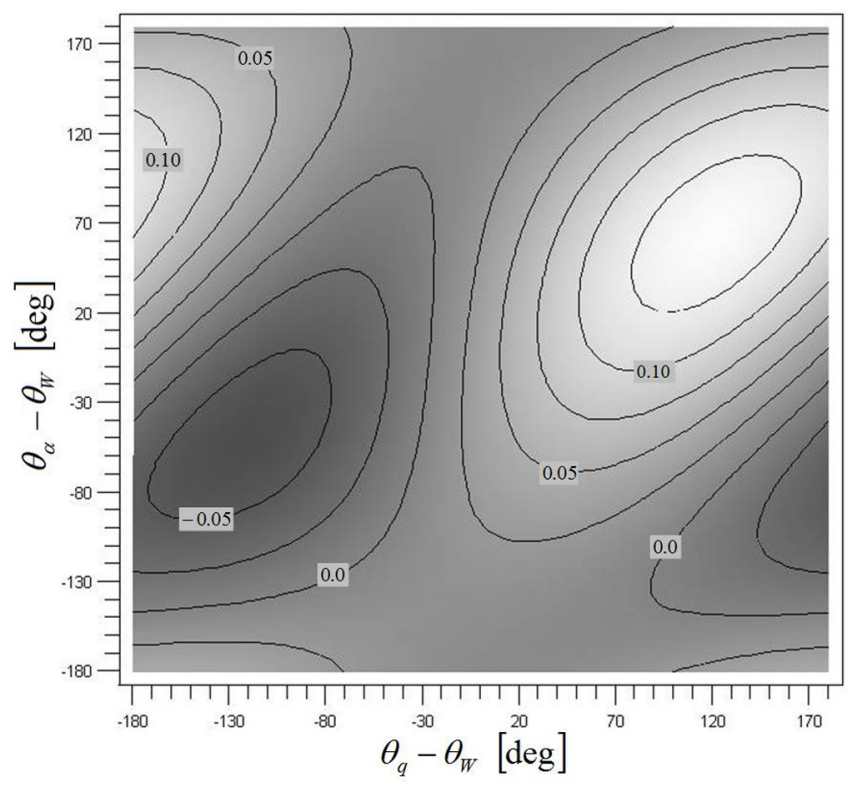

Fig. 10 Contours of $C_{P}$ for $a / l=-1 / 4,\left|q_{0} / l\right|=0.1,\left|\alpha_{0}\right|=0.2$, $|W / U|=0.2, \mu=0.0$, and $k=0.5$

값을 살펴보기 위해 Table 1의 조건들 중 $a / l=-1 / 4,\left|q_{0} / l\right|=0.1$, $\left|\alpha_{0}\right|=0.2$, 그리고 $|W / U|=0.2$ 에 대한 해석 결과를 Fig. 10 에 도시 하였다. 이 때 $k=0.5$ 이다. 그림에서 보듯이 $\theta_{q}-\theta_{W}=-135^{\circ}$ 그리 고 $\theta_{\alpha}-\theta_{W}=-45^{\circ}$ 부근에서 상대적으로 큰 음의 $C_{P}$ 값을 보인다. 반면에 $\theta_{q}-\theta_{W}=120^{\circ}, \theta_{\alpha}-\theta_{W}=60^{\circ}$ 부근에서는 큰 양의 $C_{P}$ 값 을 보여 날개운동을 위해 동력이 많이 소모됨을 알 수 있다.

그러나 동요하는 날개의 기능은 운송체의 운동제어를 위한 변동양력발생(예를 들면 핀 안정기 등), 조류나 어류의 유체동 역학적 추력 발생, 조류에너지(Current energy) 추출 등 다양하므 로, 이러한 주요기능을 고려하여 상하동요, 종동요, 파동유장의 크기들과 상호간의 위상차, 그리고 회전점의 위치 등에 따른 동 력의 변화를 살펴보아야 할 것이다.

\section{7. 결 론}

전파하는 파동 수직유장 중 전진하며 동요하는 2 차원 날개에 소요되는 동력을 해석하였다. 섭동법에 근거하여 2차항의 비선 형 물리량인 동력을 날개의 상하동요, 종동요, 그리고 파동유속 의 곱에 대응하는 2 차 전달함수들로 표현하였다. 종동요 크기의 제곱에 대응하는 2 차 전달 함수 해석결과 회전점이 뒷전 쪽 $a / l=-1.4$ 에 위치 할 때 종동요를 위한 필요 동력이 매우 작음 을 확인 하였다. 그리고 상하동요, 종동요, 파동유속 들 간의 위 상차에 대한 해석결과를 보면 동력 값이 위상차들에 대해 상당 히 민감함을 알 수 있다. 해석 예를 통해 이러한 위상차들을 적
절한 값으로 선택하면 날개 동요를 위한 최소 또는 음의 동력 상태를 구현 할 수 있음을 보였다.

본 연구결과를 활용하면 동요하는 날개의 소요 동력을 추정 할 수 있고, 동요 및 파동류의 크기와 상호간의 위상차, 회전점 의 위치 등에 대한 매개변수 해석(Parametric study)을 통해 날개 구동기구에 대한 최적 설계에 적용가능하리라 생각된다.

\section{References}

Azuma, A., 2006. The Biokinetics of Flying and Swimming. $2^{\text {nd }}$ Edition, AIAA, Reston, VA.

Choi, Y.-R., 2012. Thrust Caused by Oscillating Two-Dimensional Hydrofoil Moving in Propagating Unsteady Flow Field. Journal of Ocean Engineering and Technology, 26(5), 40-46. https:// doi.org/10.5574/KSOE.2012.26.5.040

Choi, Y.-R., 2013. Propulsion by Oscillating Foil Attached to Ship in Waves. J. of Ocean Engineering and Technology, 27(1), 31-36. https://doi.org/10.5574/KSOE.2013.27.1.031

Garrick, I.R., 1936. Propulsion of a Flapping and Oscillating Airfoil. NACA Report No. 567.

Greenberg, J.M., 1947. Some Consideration on an Airfoil in an Oscillating Stream. NACA Technical Note No. 1372.

Kaplan, P., 1955. A Hydrodynamic Theory for the Forces on Hydrofoils in Unsteady Motion. Sc.D. Thesis, Stevens Institute of Technology.

Lighthill, M.J., 1975. Mathematical Biofluiddynamics, Society for Industrial and Applied Mathematics, Philadelphia, PA.

Newman, J.N., 1977. Marine Hydrodynamics. MIT Press, Cambridge, MA.

Perez, T., 2005. Ship Motion Control: Course Keeping and Roll Reduction using Rudder and Fins. Springer-Verlag, London, UK.

Sears, W.R., 1941. Some Aspects of Non-Stationary Airfoil Theory and Its Practical Application. Journal of Aeronautical Sciences, 8(3), 104-108. https://doi.org/10.2514/8.10655

Theodorsen, T., 1935. General Theory of Aerodynamic Instability and the Mechanism of Flutter. NACA Report No. 496.

Wu, T.Y., 1971. Hydrodynamics of Swimming Propulsion. Part 1. Swimming of a Two-Dimensional Flexible Plate at Variable Forward Speeds in an Inviscid Fluid. Journal of Fluid Mech., 46(2), 337-355. https://doi.org/10.1017/S0022112071000570

Xiao, Q., Zhu, Q., 2014. A Review on Flow Energy Harvesters Based on Flapping Foils. J. of Fluids and Structures, 46, 174-191. 